Jurnal Satyagraha, Vol. 01, No. 02, Agustus 2018 - Januari 2019 ISSN : 2620-6358

\title{
PENGARUH MOTIVASI, KEPEMIMPINAN DAN DISIPLIN KERJA TERHADAP KINERJA KARYAWAN RUMAH SAKIT UMUM DAERAH WANGAYA KOTA DENPASAR
}

\author{
Ni Ketut Murdani ${ }^{1}$ \\ Ni Luh Ketut Ayu Sudha Sucandrawati ${ }^{2}$ \\ I Dewa Nyoman Usadha ${ }^{3}$ \\ Program Studi Manajemen, Fakultas Ekonomi, Universitas Mahendradatta \\ Jl. Ken Arok No 12, Peguyangan Denpasar Utara, Bali 80115 \\ Email : ketutmurdani82@yahoo.com
}

\begin{abstract}
Abstrak - Keberhasilan perusahaan sangat dipengaruhi oleh kinerja karyawannya. Kinerja yang baik adalah kinerja yang optimal, yaitu kinerja yang sesuai standar organisasi dan mendukung tercapainya tujuan organisasi. Setiap perusahaan akan berusaha untuk selalu meningkatkan kinerja karyawannya demi tercapainya tujuan yang telah ditetapkan perusahaan. Adapun tujuan penelitian ini adalah : 1) Untuk mengetahui pengaruh motivasi terhadap kinerja karyawan RSUD Wangaya Kota Denpasar; 2) Untuk mengetahui pengaruh kepemimpinan terhadap kinerja karyawan RSUD Wangaya Kota Denpasar; 3) Untuk mengetahui pengaruh disiplin kerja terhadap kinerja karyawan RSUD Wangaya Kota Denpasar; dan 4) Untuk mengetahui apakah motivasi, kepemimpinan dan disiplin kerja berpengaruh secara bersama-sama terhadap kinerja karyawan RSUD Wangaya Kota Denpasar. Metode Analisis Data yang digunakan dalam penelitian ini adalah analisis data kuantitatif menggunakan program SPSS (Statistical Package for Social Science) for windows version 21.

Hasil yang diperoleh dari penelitian ini adalah Motivasi tidak berpengaruh signifikan terhadap kinerja karyawan pada RSUD Wangaya Kota Denpasar sebesar 0,111 atau $11 \%$ dimana nilai signifikan 0,106 atau lebih besar dari level of significant ( $\alpha$ ) 0,05 Kepemimpinan berpengaruh signifikan terhadap kinerja karyawan pada RSUD Wangaya Kota Denpasar sebersar 0,210 atau $21 \%$ dimana nilai signifikan 0,000 atau lebih kecil dari level of significant ( $\alpha$ ) 0,05. Disiplin kerja tidak berpengaruh signifikan terhadap kinerja karyawan pada RSUD Wangaya Kota Denpasar sebesar 0,051 atau $5 \%$ dimana nilai signifikan 0,477 atau lebih besar dari level of significant ( $\alpha$ ) 0,05. Motivasi, kepemimpinan dan disiplin kerja secara bersama - sama berpengaruh terhadap kinerja karyawan RSUD Wangaya Kota Denpasar sebesar 0,67 atau $67 \%$ sisanya sebesar $33 \%$ dipengaruhi oleh variabel yang tidak diteliti dalam penelitian ini. Dimana nilai signifikannya 0,000 atau lebih kecil dari levels of significant $(\alpha)$ 0,05.
\end{abstract}

Ni Ketut Murdani

Ni Luh Ketut Sudha Sucandrawati 
Keyword : motivasi, kepemimpinan, didiplin kerja, kinerja karyawan.

Abstract - The success of the company is strongly influenced by the performance of its employees. Good performance is the optimal performance, that is, performance that conforms to the organization's standards and supports the achievement of organizational goals. Each company will strive to always improve the performance of its employees in order to achieve the goals set by the company.The purpose of this study are: 1) To determine the effect of motivation on employee performance Wangaya Denpasar Hospital; 2) To know the influence of leadership on employee performance of RSUD Wangaya Denpasar City; 3) To know the influence of work discipline on employee performance of Wangaya Hospital Denpasar City; and 4) To find out whether the motivation, leadership and work discipline affect together on the performance of employees of Wangaya Hospital Denpasar City. Data Analysis Method used in this research is quantitative data analysis and analyze by using program of SPSS ( Statistical Package for Social Science) for windows version 21 .

The result of this research is that the motivation has no significant effect to the employee performance at RSUD Wangaya Kota Denpasar of 0,111 or 11\% where significant value 0,106 or bigger than level of significant $(\alpha)$ 0,05 Leadership significant to employee performance at RSUD Wangaya Denpasar city sebersar 0,210 or $21 \%$ where significant value 0.000 or smaller than level of significant ( $\alpha$ ) 0,05. Work discipline has no significant effect on employee performance at RSUD Wangaya Kota Denpasar of 0,051 or 5\% where significant value 0,477 or bigger than level of significant $(\alpha)$ 0,05. Motivation, leadership and work discipline together affect the performance of employees of Wangaya Hospital Denpasar City of 0.67 or $67 \%$ of the rest by $33 \%$ influenced by the variable not examined in this study. Where the significance value is 0.000 or smaller than the 0.05 level of significant $(\alpha) 0,05$.

Keyword: motivation, leadership, discipline work, employee performance.

Ni Ketut Murdani 


\section{PENDAHULUAN}

Faktor internal suatu organisasi yaitu faktor yang bersumber dari dalam organisasi berupa sumber daya manusia (SDM). Sumber daya manusia di dalam perusahaan sebagai pilar utama dan poros penggerak roda perusahaan untuk mewujudkan visi dan misi perusahaan. Para karyawan yang memiliki bakat, tenaga, kreativitas adalah sumber daya manusia yang dibutuhkan perusahaan untuk mencapai tujuan. Potensi sumber daya manusia perlu dikembangkan dan diperhatikan agar menjadi sumber daya manusia yang professional dan berkualitas serta berdampak pada keberhasilan perusahaan.

Keberhasilan perusahaan sangat dipengaruhi oleh kinerja karyawannya. Kinerja yang baik adalah kinerja yang optimal, yaitu kinerja yang sesuai standar organisasi dan mendukung tercapainya tujuan organisasi. Kinerja merupakan prestasi kerja, yakni perbandingan antara hasil kerja yang secara nyata dengan standar kerja yang ditetapkan (Dessler, 1992). Setiap perusahaan akan berusaha untuk selalu meningkatkan kinerja karyawannya demi tercapainya tujuan yang telah ditetapkan perusahaan. Terdapat faktor negatif yang dapat menurunkan kinerja karyawan, diantaranya adalah menurunnya keinginan karyawan untuk mencapai prestasi kerja, tingkat absensi yang kurang serta kurangnya ketepatan waktu dalam penyelesaian pekerjaan sehingga kurang menaati peraturan, serta program kerja yang tidak tercapai.

Semua proses kegiatan dalam bekerja pada akhirnya akan menghasilkan kinerja karyawan yang diinginkan sesuai dengan tujuan perusahaan. Kaitanya dengan kinerja karyawan dalam memberikan perhatian pada penelitian dan pengembangan pada sumber daya manusianya. Dengan melihat pengaruh dari motivasi, kepemimpinan dan disiplin kerja karyawan dapat dijadikan pembelajaran untuk meningkatkan kinerja karyawan.

Pada penelitian ini penulis membatasi masalah yang akan dikemukakan yaitu pengaruh motivasi, kepemimpinan dan disiplin kerja terhadap kinerja karyawan RSUD Wangaya Kota Denpasar.

Adapun tujuan penelitian ini adalah : 1) Untuk mengetahui pengaruh motivasi terhadap kinerja karyawan RSUD Wangaya Kota Denpasar; 2) Untuk mengetahui pengaruh kepemimpinan terhadap kinerja karyawan RSUD Wangaya Kota Denpasar; 3) Untuk mengetahui pengaruh disiplin kerja terhadap kinerja karyawan RSUD Wangaya Kota Denpasar; dan 4) Untuk mengetahui apakah motivasi,

Ni Luh Ketut Sudha Sucandrawati 
kepemimpinan dan disiplin kerja berpengaruh secara bersama-sama terhadap kinerja karyawan RSUD Wangaya Kota Denpasar.

\section{KAJIAN PUSTAKA}

\section{Motivasi}

Menurut Mathis (2001) merupakan hasrat dalam diri seseorang yang menyebabkan orang tersebut melakukan tindakan. Mengerti motivasi adalah penting karena kinerja reaksi terhadap kompensasi dan perhatian sumber daya manusia lainya yang berhubungan dengan motivasi tersebut.

Maslow dalam Munandar (2008) menjelaskan individu dimotivasi oleh kebutuhan yang belum dipuaskan, yang paling rendah, paling dasar dalam tata tingkat. Selanjutnya dijelaskan bahwa individu dimotivasi oleh kebutuhan yang belum dipuaskan, yang paling rendah, paling dasar dalam tata tingkat. Begitu tingkat ini dipuaskan, individu tersebut tidak akan lagi memotivasi perilaku. Kebutuhan pada tingkat berikutnya yang lebih tinggi menjadi dominan. Dua tingkat kebutuhan dapat beroperasi pada waktu yang sama, tetapi kebutuhan pada tingkat lebih rendah yang dianggap menjadi motivator yang lebih kuat dari menekankan bahwa makin tinggi tingkat kebutuhan, makin tidak penting individu tersebut untuk mempertahankan hidup (survival) dan makin lama pemenuhannya dapat ditunda.

Luthans (2006) menjelaskan motivasi adalah proses yang dimulai dengan definisi fisiologis atau psikologis yang menggerakkan perilaku atau dorongan yang ditujukan untuk tujuan atau insentif. Dengan demikian, kunci untuk memahami proses motivasi bergantung pada pengertian dan hubungan antara kebutuhan, dorongan, dan insentif.

\section{Kepemimpinan}

Kepemimpinan merupakan kemampuan untuk mempengaruhi suatu kelompok kearah tercapainya suatu tujuan. Kepemimpinan adalah pribadi yang dijalankan dalam situasi tertentu, serta diarahkan melalui proses komunikasi kearah pencapaian satu atau beberapa tujuan tertentu. Kepemimpinan menyangkut proses pengaruh sosial yang disengaja dijalankan oleh seseorang terhadap orang lain untuk menstruktur aktivitas dan pengaruh didalam kelompok atau organisasi (Robbins, 2006).

Kartini (1994), menyatakan bahwa fungsi kepemimpinan adalah memandu, menuntun, membimbing, membangun, memberi atau membangun motivasi kerja, 
mengemudikan organisasi, menjaring jaringan komunikasi dan membawa pengikutnya kepada sasaran yang ingin dituju dengan ketentuan waktu dan perencanaan.

George R. Terry (1985), mengatakan bahwa kepemimpinan adalah merupakan hubungan antara seseorang dengan orang lain, pemimpin mampu mempengaruhi orang lain agar bersedia bekerja bersama-sama dalam tugas yang berkaitan untuk mencapai tujuan yang diinginkan. Sedang Konz (1989), mendefinisikan kepemimpinan sebagai seni membujuk bawahan agar mau mengerjakan tugas-tugas dengan yakin dan semangat.

Kepemimpinan adalah pribadi yang dijalankan dalam situasi tertentu, serta diarahkan melalui proses komunikasi kearah pencapaian satu atau beberapa tujuan tertentu. Kepemimpinan menyangkut proses pengaruh sosial yang disengaja dijalankan oleh seseorang terhadap orang lain untuk menstruktur aktivitas dan pengaruh didalam kelompok atau organisasi (Robbins, 2006).

Sing-Sengupta, Sunita (1997) dalam Fuad Mas'ud (2004), mengatakan gaya kepemimpinan terdiri dari empat dimensi gaya kepemimpinan yaitu: 1) Gaya Otoriter, yaitu gaya kepemimpinan yang tidak membutuhkan pokok pokok pikiran dari bawahan dan mengutamakan kekuasaan serta prestise sehingga seorang pemimpin mempunyai kepercayaan diri yang tinggi dalam pengambilan keputusan (Singh-Sengupta, Sunita, 1997 dalam Fuad Mas'ud 2004); 2) Gaya Pengasuh, yaitu gaya kepemimpinan dimana pemimpin memperhatikan bawahan dalam peningkatan karier, memberikanbimbingan, arahan, bantuan dan bersikap baik serta menghargai bawahanyang bekerja dengan tepat waktu (Sing-Sengupta, Sunita, 1997 dalamFuad Mas'ud, 2004); 3) Gaya Berorientasi pada tugas, yaitu gaya kepemimpinan dimana seorang pemimpin menuntut bawahan untuk disiplin dalam hal pekerjaan atau tugas (SinghSengupta, Sunita, 1997 dalam Fuad Mas'ud, 2004); 4) Gaya Partisipatif, yaitu gaya kepemimpinan dimana pemimpin mengharapkan saran-saran dan ide-ide dari bawahan sebelum mengambil suatu keputusan (House dan Mitchell, 1974 dalam Yulk, 1989).

\section{Disiplin Kerja}

Dispilin merupakan suatu keadaan tertentu dimana orang-orang yang tergabung dalam organisasi tunduk pada peraturan-peraturan yang ada dengan rasa senang hati. Sedangkan kerja adalah segala aktivitas manusia yang dilakukan untuk menggapai tujuan yang telah ditetapkannya. 
Menurut Malayu S.P Hasibuan (1996:212) bahwa "Kedisiplinan adalah kesadaran dan kesediaan seseorang mentaati semua peraruran perusahaan dan norma-norma yang berlaku".

Soegeng Prijodarminto. (1993:16) berpendapat "Displin berbagi pada tiga aspek yaitu sikap mental, pemahaman, dan sikap kelaukuan, diuraikan sebagai berikut:

1) Sikap mental (mental attitude), yang merupakan sikap taat dan tertib sebagai hasil atau pengembangan dari latihan, pengendalian pikiran pikiran dan pengendalian watak; 2) Pemahaman yang baik mengebai system aturan perilaku, norma, kriteria, dan standar yang sedemikian rupa sehingga pemahaman tersebut menumbuhkan pengertian yang mendalam atau kesadaran, bahwa ketaatan akan aturan, norma, criteria dan standar tadi merupakan syarat mutlak untuk mencapai keberhasilan (sukses); 3) Sikap kelakuan yang secara wajar menunjukkan kesanggupan hati, untuk mentaati segala hal secara cermat dan tertib.

Disiplin merupakan sarana untuk melatih kepribadian pegawai agar senantiasa menunjukkan kinerja yang baik sikap, perilaku dan pola kehidupan yang baik dan berdisiplin tidak berbentuk dalam waktu yang lama salah satu proses untuk membentuk kepribadian tersebut dilakukan melaui proses latihan. Latihan tersebut dilaksanakan

Ni Ketut Murdani

Ni Luh Ketut Sudha Sucandrawati bersama dilaksanakan bersama antar pegawai, pimpinan dan selurih personil yang ada dalam organisasi tersebut.

Disiplin berfungsi sebagai pemaksaan kepada seseorang untuk mengikuti peraturan-peraturan yang berlaku di lingkungan tersebut dengan pemaksaan, pembiasaan, dan latihan disiplin seperti itu dapat menyadarkan bahwa diplin itu penting.

\section{Kinerja Karyawan}

Kinerja merupakan perilaku organisasi yang secara langsung berhubungan dengan produksi barang atau penyampaian jasa. Informasi tentang kinerja organisasi merupakan suatu hal yang sangat penting digunakan untuk mengevaluasi apakah proses kinerja yang dilakukan organisasi selama ini sudah sejalan dengan tujuan yang diharapkan atau belum.

Kinerja sebagai hasil-hasil fungsi pekerjaan/kegiatan seseorang atau kelompok dalam suatu organisasi yang dipengaruhi oleh berbagai faktor untuk mencapai tujuan organisasi dalam periode waktu tertentu (Tika, 2006). Menurut Bambang Guritno dan Waridin (2005) kinerja merupakan perbandingan hasil kerja yang dicapai oleh karyawan dengan standar yang telah ditentukan. Sedangkan menurut Hakim (2006) mendefinisikan kinerja sebagai hasil kerja yang dicapai oleh 
individu yang disesuaikan dengan peran atau tugas individu tersebut dalam suatu perusahaan pada suatu periode waktu tertentu, yang dihubungkan dengan suatu ukuran nilai atau standar tertentu dari perusahaan dimana individu tersebut bekerja. Kinerja merupakan perbandingan hasil kerja yang dicapai oleh pegawai dengan standar yang telah ditentukan (Masrukhin dan Waridin, 2004).

Kinerja karyawan merupakan proses sampai hasil kerja yang dilaksanakan untuk pencapaian tugas sesuai dengan tujuan perusahaan. Suatu keberhasilan perusahaan dapat dilihat dari prestasi atau pelaksanaan kerja karyawan karena karyawan merupakan salah satu sumber daya penggerak perusahaan.

Kinerja karyawan dapat dilihat dari membandingkan standar kerja yang sudah ada, target atau kriteria yang telah ditentukan oleh organisasi dalam periode tertentu.

\section{METODE PENELITIAN}

Adapun variabel - variabel yang akan diteliti dalam penelitian ini adalah:

1. Motivasi (variabel X1)

Motivasi merupakan faktor yang mempengaruhi semangat dan kegairahan kerja karyawan untuk berperan serta secara aktif dalam proses kerja. Teori motivasi yang paling terkenal adalah hirarki kebutuhan yang diungkapan Abraham Maslow. Hipotesisnya mengatakan bahwa di dalam diri semua manusia bersemayam lima jenjang kebutuhan (Maslow, dalam Robbins, 2006), yang menjadi indikator yaitu:
a. Kebutuhan fisiologis
b. Kebutuhan rasa aman
c. Kebutuhan sosial
d. Kebutuhan penghargaan
e. Kebutuhan aktualisasi diri

2. Kepemimpinan (variabel X2)

Gaya kepemimpinan adalah suatu cara pemimpin untuk mempengaruhi bawahannya agar mau bekerja secara produktif untuk mencapai tujuan organisasi (Hasibuan,2008:170). Adapun indikator kepemimpinan (Pundjojo, 2000:222) yaitu :

a. Keinginan menerima tanggung jawab

b. Kemampuan persepsi

c. Kemampuan berkomunikasi

d. Kemampuan untuk menentukan prioritas

e. Kemampuan untuk untuk bersikap obyektif

3. Disiplin Kerja (variabel x3)

Disiplin Kerja adalah suatu sikap dan perilaku karyawan untuk mentaati dan menyesuaikan peraturan yang berlaku dalam oraganisasi dengan didasarkan atas kesadaran diri. Adapun indikator disiplin kerja yaitu : 
a. Frekuensi kehadiran karyawan di kantor pada hari-hari kerja serta ketepatan jam masuk dan pulang kerja.

b. Ketaatan pada peraturan yang berlaku yaitu pada waktu bekerja

c. Kepatuhan terhadap tata tertib.

4. Kinerja Karyawan (variabel Y) Kinerja karyawan adalah perbandingan hasil kerja nyata karyawan dengan standar kerja yang telah ditetapkan oleh perusahaan. Beberapa indikator untuk mengukur sejauh mana pegawai mencapai suatu kinerja secara individual menurut Robert L. Mathis dan John H. Jackson (2006:378) adalah sebagai berikut:
a. Kuantitas
b. Kualitas
c. Keandalan
d. Kehadiran
e. Kemampuan Bekerjasama

\section{Teknik Analisis Data}

Analisis Data yang digunakan dalam penelitian ini adalah analisis data kuantitatif yaitu bentuk analisa yang menggunakan angka - angka dan perhitungan dengan metode statistik, maka data tersebut harus diklsifikasikan dalam kategori tertentu dengan menggunakan tabel tabel tertentu, untuk mempermudah dalam menganalisis dengan menggunakan program SPSS (Statistical Package for Social Science) for windows version 21.

\section{Gambaran Umum Perusahaan}

RSUD Wangaya diperkirakan berdiri pada tahun 1921 oleh Pemerintah Hindia-Belanda, yang merupakan Rumah Sakit tertua di Bali. Sewaktu didirikannya, rumah sakit ini hanya memiliki 30 buah tempat tidur. Pada tahun 1942 terjadi pengalihan kekuasaan dari Pemerintah Hindia-Belanda kepada Pemerintah Jepang, sehingga RSUD Wangaya dengan otomatis dikelola oleh Pemerintah Jepang.

Pada tahun 1945 sampai dengan tahun 1950, RSUD Wangaya dibawah pengelolaan Negara Indonesia Timur (NIT), dan pada waktu itu terjadi revolusi fisik, sehingga RSUD Wangaya dimanfaatkan sebagai salah satu sarana penunjang dalam perjuangan karena itu RSUD Wangaya juga dikenal sebagai Rumah Sakit Pejuang.

Dengan terjadinya perubahan pada sistem pemerintahan yaitu pada tahun 1951 sampai dengan 1958, maka pengelolaan RSUD Wangaya berada di bawah Pemerintahan Propinsi Sunda Kecil.

Setelah terbentuknya Pemerintahan Propinsi Dati I Bali pada tahun 1958, maka sejak tahun 
tersebut RSUD Wangaya menjadi Rumah Sakit Daerah Propinsi Dati I Bali, yang diklasifikasikan ke dalam Rumah Sakit Kelas D. Selanjutnya, dengan diterbitkannya Surat Keputusan Gubernur Kepala Daerah Tingkat I Bali Nomor 287 Tahun 1986, maka status RSUD Wangaya ditingkatkan dari Kelas D menjadi Kelas C, yang diperkuat dengan Surat Keputusan Menteri Kesehatan Republik Indonesia Nomor: 009-K / Menkes / SK / I / 1993, tanggal 9 Januari 1993.

Dengan terbentuknya Pemerintah Kotamadya Dati II Denpasar berdasarkan Undangundang Nomor 1 Tahun 1992, tanggal 27 Pebruari 1992, maka mulai tanggal 1 Juni 1993, RSUD Wangaya menjadi Rumah Sakit Kotamadya Dati II Denpasar.

Sejak bergulirnya Otonomi Daerah, Pemerintah Kota Denpasar meningkatkan status RSUD Wangaya menjadi Rumah Sakit Swadana berdasarkan Peraturan Daerah Kota Denpasar Nomor 23 Tahun 2001, dan merubah nomenklatur serta susunan organisasi RSUD Wangaya menjadi Badan Pelayanan Rumah Sakit Umum Daerah Wangaya Kota Denpasar berdasarkan Peraturan Daerah Kota Denpasar Nomor: 22 Tahun 2001, tanggal 3 Desember 2001.

Dengan keluarnya Peraturan Pemerintah RI Nomor 23 Tahun 2005 tentang Pola Pengelolaan Keuangan Badan Layanan Umum Daerah (PPKBLUD) dan Peraturan Menteri dalam Negeri Nomor 61 Tahun 2007 tentang Pedoman Teknis Pengelolaan Keuangan Badan layanan Umum, Rumah Sakit Umum Daerah Wangaya Kota Denpasar mulai mempersiapkan diri menuju Badan Layanan Umum (BLU) dengan menyusun Bisnis Plan, Tata Kelola, penyempurnaan laporan keuangan dan menyusun Standar Pelayanan Minimal. Tanggal 23 Juli 2008 dengan Keputusan Walikota Denpasar Nomor 96 Tahun 2008, Rumah Sakit Umum Daerah Wangaya Kota Denpasar ditetapkan menjadi PPK BLUD dengan status BLUD penuh serta merubah Nomenklaturnya menjadi Rumah Sakit Umum Daerah Wangaya Kota Denpasar dengan Peraturan Daerah Kota Denpasar Nomor 8 Tahun 2008 tentang Organisasi dan Tata Kerja Lembaga Teknis Daerah Kota Denpasar.

\section{PEMBAHASAN}

Hasil Analisis Regresi Linier Berganda diperoleh persamaan $\mathrm{Y}=$ $22,916+0,111 \mathrm{X}_{1}+0,210 \mathrm{X}_{2}+$ $0,051 X_{3}+$ e. Ini berarti bahwa terdapat pengaruh yang signifikant antara motivasi, kepemimpinan dan disiplin kerja terhadap kinerja karyawan pada RSUD Wangaya Kota Denpasar adalah sebesar 22,9\%. 
Hasil analisis korelasi berganda diketahui angka korelasi antara variabel motivasi $\left(\mathrm{X}_{1}\right)$, Kepemimpinan $\left(\mathrm{X}_{2}\right)$ dan Disiplin Kerja $\left(\mathrm{X}_{3}\right)$ dengan variabel kinerja karyawan (Y) yaitu sebesar 0,260. Hasil analisis koefisien determinasi adalah 0,67 berarti besarnya pengaruh motivasi, kepemimpinan dan disiplin kerja secara bersamaan terhadap kinerja karyawan RSUD Wangaya Kota Denpasar sebesar $67 \%$ dan sisanya sebesar $33 \%$ dipengaruhi oleh selain variabel motivasi, kepemimpinan dan disiplin kerja misalnya semangat kerja, iklin kerja, kompetensi, kompensasi dan sebagainya. Hasil uji $t$ untuk pengaruh motivasi terhadap kinerja karyawan RSUD Wangaya menghasilkan t-hitung 1,624 atau dengan nilai signifikan 0,106 atau lebih besar dari level of significant $(\alpha)$ 0,05 .

Dari uji t ini dapat disimpulkan bahwa motivasi tidak berpengaruh signifikan terhadap kinerja karyawan pada RSUD Wangaya Kota Denpasar sehingga bertuk pengujian hipotesisnya adalah Ho diterima.

\section{SIMPULAN}

Motivasi tidak berpengaruh signifikan terhadap kinerja karyawan pada RSUD Wangaya Kota Denpasar sebesar 0,111 atau $11 \%$ dimana nilai signifikan 0,106 atau lebih besar dari level of significant $(\alpha)$ 0,05. signifikan terhadap kinerja karyawan pada RSUD Wangaya Kota Denpasar sebersar 0,210 atau $21 \%$ dimana nilai signifikan 0,000 atau lebih kecil dari level of significant $(\alpha)$ 0,05 .

Disiplin kerja tidak berpengaruh signifikan terhadap kinerja karyawan pada RSUD Wangaya Kota Denpasar sebesar 0,051 atau $5 \%$ dimana nilai signifikan 0,477 atau lebih besar dari level of significant ( $\alpha$ ) 0,05.

Motivasi, kepemimpinan dan disiplin kerja secara bersama - sama berpengaruh terhadap kinerja karyawan RSUD Wangaya Kota Denpasar sebesar 0,67 atau 67 sisanya sebesar $33 \%$ dipengaruhi oleh variabel yang tidak diteliti dalam penelitian ini. Dimana nilai signifikannya 0,000 atau lebih kecil dari levels of significant $(\alpha) 0,05$.

\section{SARAN}

Untuk motivasi kerja pada RSUD Wangaya Kota Denpasar disarankan agar semua karyawan mampu bekerja sama dalam bekerja agar tercipta rasa kebersamaan dan karyawan diberikan tunjangantunjangan yang mampu meningkatkan prestasi kerja.

Untuk kepemimpinan pada RSUD Wangaya Kota Denpasar disarankan agar pimpinan memberikan contoh yang baik kepada bawahannya dan pimpinan juga harus memiliki pengetahuan yang tinggi

Ni Ketut Murdani

Ni Luh Ketut Sudha Sucandrawati 
dalam pekerjaannya.

Untuk Disiplin kerja pada RSUD Wangaya Kota Denpasar disarankan agar semua pegawai mampu menaati peraturan yang ada dan mampu bertanggungjawab terhadap tugas yang telah diberikan.

Untuk kinerja pada RSUD Wangaya Kota Denpasar disarankan agar semua pegawai dapat saling membantu apabila terjadi masalah dan diharapkan mampu memperoleh hasil yang memuaskan di setiap pekerjaan yang dilakukan.

\section{DAFTAR PUSTAKA}

Abdillah dan Wajdi. 2011. Pengaruh Kepemimpinan, Stres Kerja, Disiplin Kerja, Dan Kompensasi Dengan Kinerja Pegawai. Jurnal Ekonomi Manajemen. UMS.Vol.12. No.1. Surakarta

Anoraga, Pandji. 1992.

Psikologi

Kepemimpinan.

Cetakan ke-2. Jakarta:

Rhineka Cipta

Aries Susanty, Sigit Wahyu Baskoro.2012. Pengaruh Motivasi Dan gaya kepemimpinan terhadap disiplin kerja serta dampaknya pada kinerja karyawan (Studi Kasus pada PT. PLN (Persero) APD Semarang). Jurnal ilmiah Program study Teknik Industri Universitas Diponegoro
Semarang

Arikunto, Suharsini, 2002, Prosedur Penelitian Suatu Pendekatan Praktek. PT. Rineka Cipta, Jakarta

Elina.2011. Pengaruh Motivasi Dan Kepemimpinan Terhadap Kinerja Pegawai Pada PT (Persero) Pelabuhan Indonesia II Cabang Panjang Bandar Lampung. Jurnal Organisasi dan Manajemen.USBRJ. Vol.I,No:1 (49-58). Bandar Lampung

Fathoni, Abdurrahmat. 2006. Manajemen Sumber Daya Manusia. PT Rineka Cipta: Jakarta

Flippo, Edwin B. 2006. Manajemen Personalia, Edisi ke-6 Alih Bahasa Moh.Masud, Erlangga, Jakarta

Ghozali, Imam. 2005. "Aplikasi Analisis Multivariate dengan program SPSS". Semarang: Badan Penerbit Universitas Diponogoro

Hadi Sutrisno. 1991. Analisa Butir Untuk Instrumen Angket, Test, dan Skala Rating. Andi Offset. Yogyakarta

Hasibuan, Melayu SP, 2000, Manajemen Sumber Daya Manusia, Bumi Aksara, Jakarta

Hasibuan, Malayu. 2004. Manajemen Sumber Daya 
Manusia. Bumi

Aksara. Jakarta

Lasahido, dkk. 2013. Pengaruh

Motivasi Dan Etos Kerja

Terhadap Kinerja Pegawai

Sekretariat Dewan Perwakilan

Rakyat Daerah (DPRD)

Provinsi Bengkulu. Vol.15

No.7. Bengkulu

Malthis, R.L dan Jackson. 2001. Manajemen Sumber Daya Manusia. Salemba Empat. Jakarta

Maslow, Abraham H, 1994, Motivasi dan Kepribadian-Teori Motivasi dengan Pendekatan Hierarki Kebutuhan Manusia, Edisi Alih Bahasa LPPM, Jakarta

Rivai, Veithzal, 2004, Manajemen Sumber Daya Manusia Untuk Perusahaan : Dari Teori ke Praktik. Rajagrafindo Persada. Jakarta

Rivai, Veithzal dan Basri. 2005. Performance Appraisal: Sistem Yang Tepat Untuk Menilai Kinerja Karyawan Dan Meningkatkan Daya Saing Perusahaan. PT RAJA GRAFINDO PERSADA. Jakarta

Robbins, Stephen. P. 2006. Perilaku organisasi. Edisi Bahasa Indonesia.Indeks Kelompok GRAMEDIA. Jakarta
Robbins, Stephen. P. dan Mary Coulter. 2005. Manajemen. Gramedia. Jakarta.

Sedarmayanti. 2009. Tata Kerja dan Produktivitas Kerja. Bandung: MandarMaju

Sugiyono. 2010. "Metode Penelitian Bisnis". Bandung: CV. Afabeta

Tika, P. 2006. Budaya Organisasi Dan Peningkatan Kinerja Perusahaan. BumiAksara. Jakarta

Umar, Husain, 2000, Metodologi Penelitian Untuk Skripsi dan Tesis Bisnis, cetakan ketiga, Penerbit PT Raja Grafindo Persada, Jakarta

Utari.2015. Pengaruh Motivasi, Kepemimpinan dan Kedisiplinan Terhadap Kinerja Pegawai (Studi Kasus Pada Dinas Pendapatan Pengelolaan Keuangan dan Aset Daerah Wonogiri). Jurnal Ekonomi dan Bisnis Universitas Muhammadiyah Surakarta. Surakarta.

Wahyuningsih, Sapti.2015. Analisis Pengaruh Gaya Kepemimpinan, Motivasi Kerja, Disiplin Kerja Dan Lingkungan Kerja Terhadap Kinerja Karyawan Kantor Pusat PT. Sun Star Motor Solo. Jurnal Ekonomi dan Bisnis Universitas Muhammadiyah Surakarta.Surakarta 
Jurnal Satyagraha, Vol. 01, No. 02, Agustus 2018 - Januari 2019 ISSN : 2620-6358 